\title{
Morphometry of the Portal Vein: Ultrasound Anatomy about 1000 Cases
}

\section{Abdoulaye Kanté1,2, Abdoulaye Koné ${ }^{3}$, Daouda Camara ${ }^{4}$, Bréhima Bengaly ${ }^{1}$, Bréhima Coulibaly ${ }^{1}$, Drissa Traoré1, Babou Ba², Mariam Daou ${ }^{3}$, Nouhoum Ongoïba ${ }^{1,2 *}$}

${ }^{1}$ Service of Surgery B. CHU Point G, Bamako, Mali

${ }^{2}$ Laboratory of Anatomy of the Faculty of Medicine and Odontostomatology, Bamako, Mali

${ }^{3}$ Imaging Department CHU Point G, Bamako, Mali

${ }^{4}$ Service of Gynecology and Obstetrics of the CHU, Kati, Mali

Email: kanteim@yahoo.fr, *ongoibano@yahoo.fr

How to cite this paper: Kanté, A., Koné, A., Camara, D., Bengaly, B., Coulibaly, B., Traoré, D., Ba, B., Daou, M. and Ongoïba, N. (2019) Morphometry of the Portal Vein: Ultrasound Anatomy about 1000 Cases. Forensic Medicine and Anatomy Research, 7, 37-43.

https://doi.org/10.4236/fmar.2019.72007

Received: October 20, 2018

Accepted: December 23, 2018

Published: January 25, 2019

Copyright $\odot 2019$ by author(s) and Scientific Research Publishing Inc. This work is licensed under the Creative Commons Attribution International License (CC BY 4.0).

http://creativecommons.org/licenses/by/4.0/

\begin{abstract}
Aim: The aim of this study is to determine from a series of 1000 cases the usual dimensions of the portal vein according to the medical ultrasound. Methodology: We realized a transverse study over 2 years (from January 2015 to December 2017). It concerned an ultrasound exploration of the portal vein. The studied population was healthy voluntary subjects visible without history of abdominal trauma and abdominal operating scar. Results: The average age was 39 years \pm 12.16 with extremes of 19 years and 70 years. The decade of $21-29$ years represented $46.2 \%$. The transverse diameter of the portal vein in its origin varied between 8 and $10 \mathrm{~mm}$ in $57.9 \%$ of the cases. The average was $9.05 \pm 2.82 \mathrm{~mm}$ with extremes of 5 and $16 \mathrm{~mm}$. The transverse diameter of the portal vein in its ending varied between 8 and $10 \mathrm{~mm}$ in $56.9 \%$. In $29.8 \%$ of the cases, the length of the portal vein was between 61 and $70 \mathrm{~mm}$ and in $8.8 \%$ between 81 and $100 \mathrm{~mm}$. The average length was $58 \pm 22.3$ $\mathrm{mm}$. Before its penetration in the liver, the portal vein divided into 2 branches in 967 cases (96.7\%) and in 3 branches in 33 cases (3.3\%). Conclusion: This original study shows the normal dimensions of the portal vein to Malian.
\end{abstract}

\section{Keywords}

Anatomy, Portal Vein, Ultrasound, Bamako-Mali

\section{Introduction}

The portal vein (PV) or the portal trunk carries blood from the diaphragmatic part of the digestive tract, the spleen and the pancreas. Its origin is situated behind the isthmus of the pancreas by the confluence of the superior mesenteric 
vein and of the splenic trunk (formed by splenic vein and inferior mesenteric vein) [1]. The cystic and the left and right gastric veins are other tributaries of the portal vein [2]. In its route the PV is oblique at the top and forward. It ends by giving at the level of the hepatic hilum, right and left branches which move away by limiting an open very obtuse angle at the top. Branches win the corresponding extremity of the cross-functional furrow then sink into the liver. The PV establishes the later plan of the hepatic pedicle [1]. Therefore, in the surgery of the liver and the biliary ways, the PV constitutes an important anatomical mark, its dimensions are variously estimated by the authors [3] [4]. The average length of the trunk wears according to Rouvière is $100 \mathrm{~mm}$ and its diameter 15 $\mathrm{mm}$. Castaing in 1999 found that the length of the PV varies between 80 and 100 and its diameter between 15 and $20 \mathrm{~mm}$ [2]. But the conditions and the exact siege of the dimensions are not specified by the authors except for Ongoiba [5].

Outside the ultrasound study realized by Ongoïba in 2003, we did not find other anatomo-ultrasound studies on the PV. To mitigate this deficit of search on the morphometry of the portal vein, we led this study with as objective to determine from a series of 1000 cases the usual dimensions of the PV according to the ultrasound.

\section{Materials and Methods}

We realized a transverse study over 2 years (between from January 2015 to December 2017). It concerned an ultrasound exploration of the PV. The studied population was healthy voluntary subjects visible without history of abdominal trauma and abdominal operating scar. The carrying subjects of the tracks of abdominal trauma or of abdominal operating scar were not included.

Three different sonographers made at the same time this examination by using the same protocol and type Aloka's same device SSD-1700 provided with a convex probe of 3.5 MHz. During the ultrasound, we spotted the PV and measured its diameters in the origin, in the ending and its length. The number of its terminal branches was counted. Diameters were measured on a longitudinal incidence. The results were expressed in millimeter.

The data were seized and analyzed on the software Ear information (version 6). The tests of $X^{2}$ and Student's were used to compare our results with those of the other authors. The threshold of meaning was fixed to 0.05 .

The test meadow which allowed us to standardize the methodology concerned 10 subjects. Then the study concerned 1000 subjects.

\section{Results}

The average age subject was $39 \pm 12.16$ years with extremes of 19 and 70 years. The age bracket of $21-29$ years represented $46.2 \%$. It was about 500 women (50\%) and of 500 men (50\%). The sex ratio was 1.0 .

700 person (70\%) lived in Bamako whereas 300 (30\%) came from 8 regions of Mali. The results of the test meadow which concerned 10 subjects are in Table 
1. The results of the second part of the study are in Tables 2-4 and Figures 1-3.

\subsection{Highlighting of the Portal Vein and Its Branches}

The frequency of the highlighting of the PV was represented in Table 2.

In $98 \%$ of the cases the transverse diameter of the portal vein was highlighted in its origin, while in its ending, the transverse diameter was highlighted in $98.5 \%$ of the cases, and at least 2 branches were seen in $100 \%$.

\subsection{Dimensions of the Portal Vein}

\subsubsection{Transverse Diameter of the Portal Vein in Its Origin}

The transverse diameter of the PV in its origin varied between 8 and $10 \mathrm{~mm}$ in $57.9 \%$ of the cases. The average was $9.05 \pm 2.82 \mathrm{~mm}$ with extremes of 5 and 16 $\mathrm{mm}$ (Figure 1).

Figure 2 shows the origin and trajectory of the portal vein.

\subsubsection{Transverse Diameter of the Portal Vein in Its Ending}

The transverse diameter of the PV in its ending varied between 8 and $10 \mathrm{~mm}$ in $56.9 \%$. The average was $9.16 \pm 2.58 \mathrm{~mm}$ with extremes of 6 and $16 \mathrm{~mm}$ (Figure 3 ).

Figure 4 shows the measurement of the transverse diameter of the vein leading to its termination.

\subsubsection{Length of the Portal Vein}

In $29.8 \%$ of the cases, the length of the portal vein was between 61 and $70 \mathrm{~mm}$ and in $8.8 \%$ between 81 and $100 \mathrm{~mm}$. The average was $58 \pm 22.3 \mathrm{~mm}$ (Figure 5).

\subsubsection{Number of Terminal Branches of the Portal Vein}

Before its penetration in the liver, the portal vein divided into 2 branches in 967

Table 1. Average dimensions of 10 portal veins according to three sonographers.

\begin{tabular}{cccccc}
$\begin{array}{c}\text { Examiners } \\
\text { Variables }(\mathrm{mm})\end{array}$ & $\begin{array}{c}\text { Sonographer } \\
\mathrm{n}^{\circ} 1\end{array}$ & $\begin{array}{c}\text { Sonographer } \\
\mathrm{n}^{\circ} 2\end{array}$ & $\begin{array}{c}\text { Sonographer } \\
\mathrm{n}^{\circ} 3\end{array}$ & $\mathrm{~F}$ & $\mathrm{P}$ \\
\hline $\begin{array}{c}\text { Transverse diameter of the PV in } \\
\text { its origin }\end{array}$ & $9.40 \pm 1.68$ & $9.65 \pm 1.67$ & $9.80 \pm 1.66$ & 0.15 & 0.8 \\
$\begin{array}{c}\text { Transverse diameter of the PV in } \\
\text { its ending }\end{array}$ \\
$\begin{array}{c}\text { Length of the PV } \\
\text { Number of terminal branches of } \\
\text { the PV }\end{array}$
\end{tabular}

Table 2. Frequency of the highlighting of the various dimensions of the PV.

\begin{tabular}{cccccc}
\hline Highlighting of the dimensions of the PV & Not seen & $\begin{array}{c}\text { Frequency } \\
\%\end{array}$ & Seen & $\begin{array}{c}\text { Frequency } \\
\%\end{array}$ & Total \\
\hline Transverse diameter of the PV in its origin & 20 & 2 & 980 & 98 & 1000 \\
Transverse diameter of the PV in its ending & 15 & 1.5 & 985 & 98.5 & 1000 \\
Length of the PV & 20 & 2 & 980 & 98 & 1000 \\
Number of terminal branches of the PV & 0 & 0 & 1000 & 100 & 1000
\end{tabular}




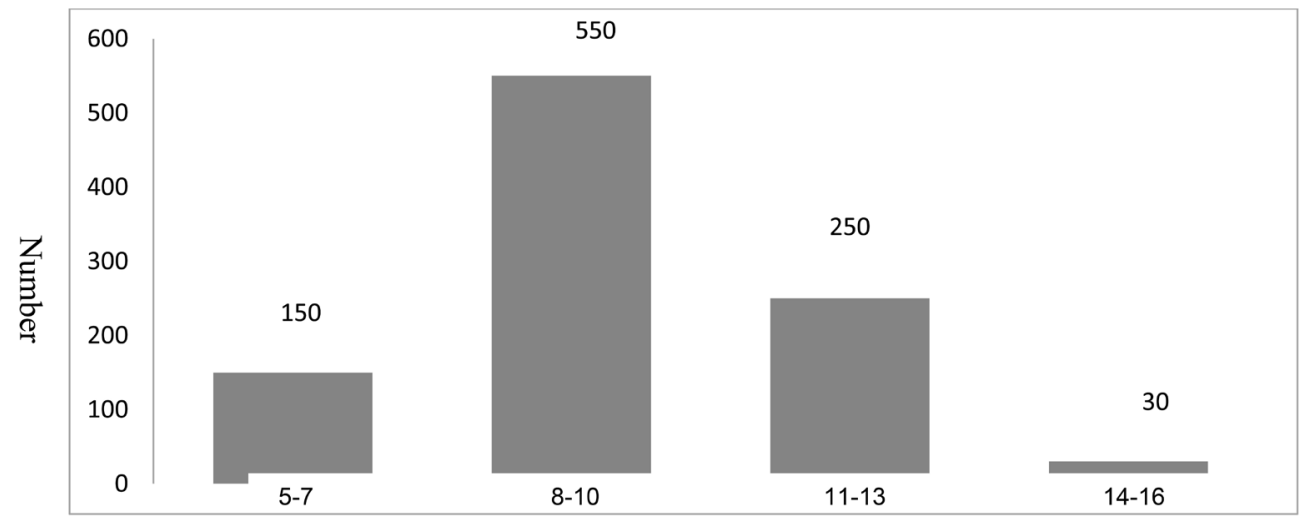

Transverse diameter of the portal vein in its origin $(\mathrm{mm})$

Figure 1. Subjects according to the transverse diameter of the portal vein in its origin.

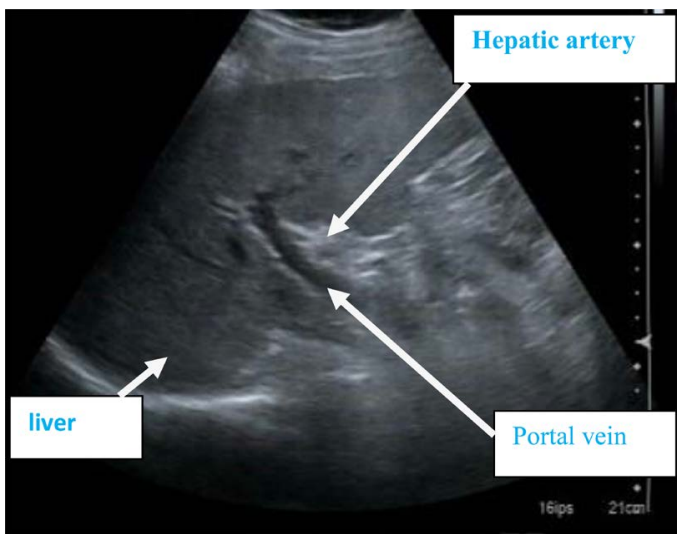

Figure 2. Ultrasound cut in mode through the hepatic hilus showing the vein measure having its origin.

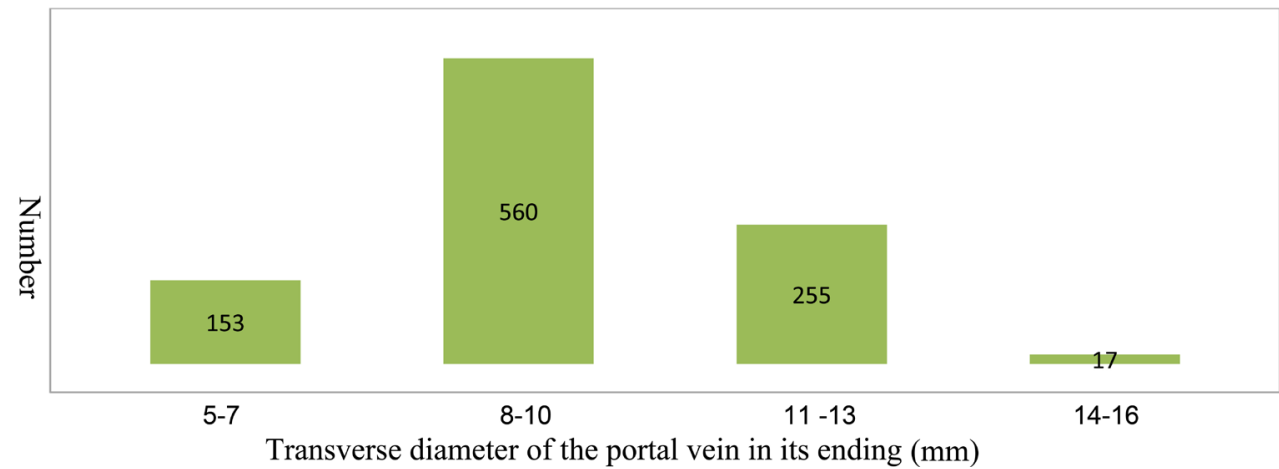

Figure 3. Subjects according to the transverse diameter of the portal vein in its ending.

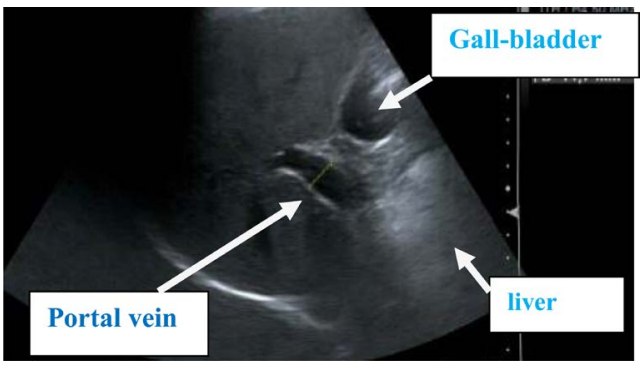

Figure 4. Ultrasonographic cut through the hepatic hilum showing the vein measure ending. 
cases $(96.7 \%)$ and in 3 branches in 33 cases (3.3\%) (Figure 6).

\subsubsection{Dimensions of the Portal Vein According to the Age}

Table 3 shows the dimensions of the portal vein before and after 20 years. To the subjects from 11 to 20 years, the average of the transverse diameter of the portal vein in its origin was $8.9 \pm 2 \mathrm{~mm}$. This diameter was $9.6 \pm 1.9 \mathrm{~mm}$ to the subjects of more than 20 years $(\mathrm{p}=0.298$ ). The difference was not significant. To the subjects from 11 to 20 years, the transverse diameter of the PV in its ending was $9.6 \pm 2 \mathrm{~mm}(\mathrm{p}=0.567)$. The difference was not significant.

\subsubsection{Dimensions of the Portal Vein According to the Sex}

Table 4 shows the dimensions of the PV according to the sex. To the male subjects, the average of the transverse diameter of the PV in its origin was $9.7 \pm 1.9$ $\mathrm{mm}$. This average was $9.3 \pm 2 \mathrm{~mm}$ to the female subjects $(\mathrm{p}=0.411)$.

To the male subjects, the average transverse diameter of the portal vein in its ending was $9.4 \pm 2.2 \mathrm{~mm}$. This average to the female subjects was $9.6 \pm 1.7$

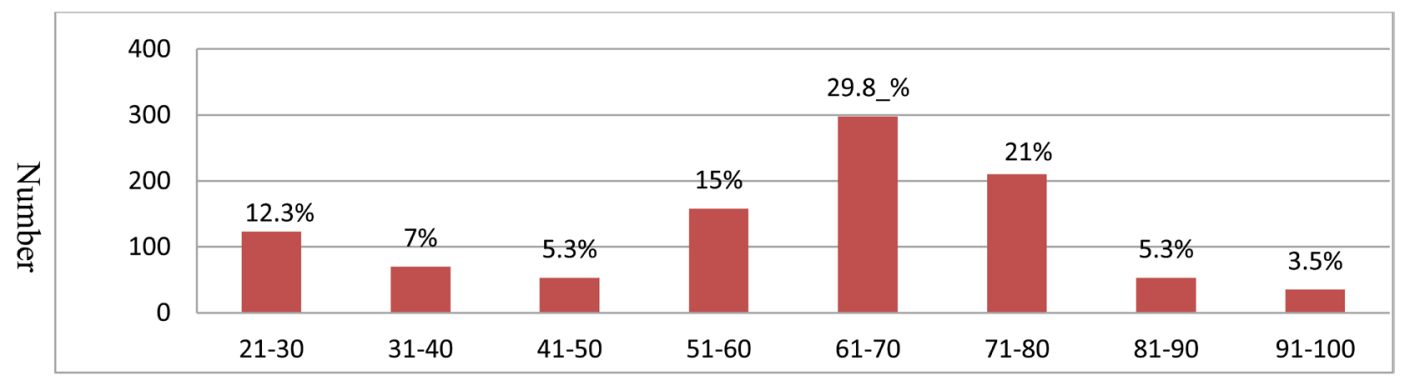

length of the portal vein $(\mathrm{mm})$

Figure 5. Subjects according to the length of the portal vein.

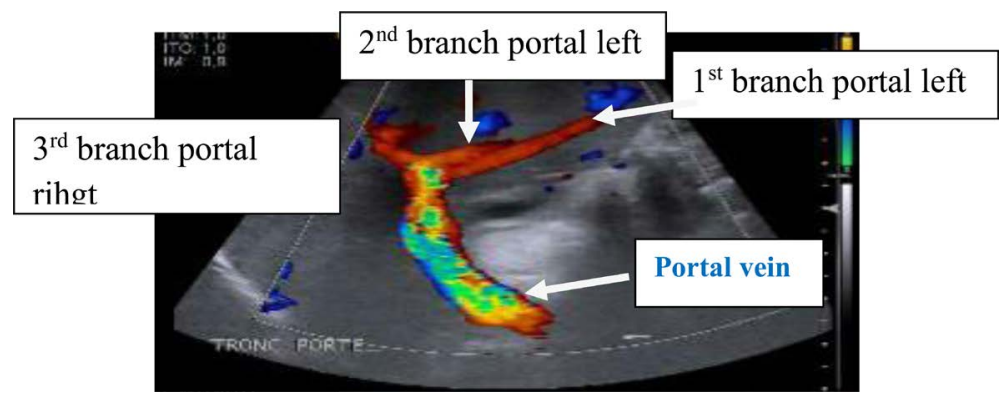

Figure 6. Color Doppler ultrasound cut through hepatic hilus showing division of vein in three branches.

Table 3. Average dimensions compared by the PV between the subjects of less than 20 years and those of more than 20 years.

\begin{tabular}{cccc}
\hline $\begin{array}{c}\text { Age in year } \\
\text { Dimensions PV }(\mathrm{mm})\end{array}$ & $\begin{array}{c}<20 \text { ans } \\
\mathrm{n}=134\end{array}$ & $\begin{array}{c}>20 \text { ans } \\
\mathrm{n}=866\end{array}$ & $\mathrm{P}$ \\
\hline Average transverse diameter of the PV in its origin & $8.8 \pm 2$ & $9.6 \pm 2$ & 0.298 \\
Average transverse diameter of the PV in its ending & $9.1 \pm 1.5$ & $9.3 \pm 2$ & 0.567 \\
Length averages of the PV & $48.8 \pm 17.6$ & $46.31 \pm 17.3$ & 0.033 \\
\hline
\end{tabular}


Table 4. Average dimensions compared by the portal vein between between the male and female subjects.

\begin{tabular}{cccc}
\hline Sex & $\begin{array}{c}\text { Male } \\
\mathrm{n}=500\end{array}$ & $\begin{array}{c}\text { Female } \\
\mathrm{n}=500\end{array}$ & $\mathrm{P}$ \\
\hline Dimensions PV $(\mathrm{mm})$ & $9.7 \pm 1.9$ & $9.3 \pm 2$ & 0.411 \\
Diameter of the PV in its origin & $9.4 \pm 2.2$ & $9.6 \pm 1.7$ & 0.730 \\
diameter of the PV in its ending & $65.2 \pm 16.4$ & $57.7 \pm 17.8$ & 0.001 \\
\hline
\end{tabular}

$\mathrm{mm}(\mathrm{p}=0.730)$.

The average length of the portal vein to the male subjects was $65.2 \pm 16.4 \mathrm{~mm}$. To the female subjects, this average was $57.7 \pm 17.8 \mathrm{~mm}$. The difference was statistically significant $(\mathrm{p}=0.001)$.

\section{Discussion}

We measured in the ultrasound the transverse diameter of the PV in its origin and in its ending and its length.

We did not find significant difference between certain dimensions (transverse diameters, original and terminals) of the vein of the subjects of less than 20 years versus the subjects of more than 20 years. We did not either find statistically significant difference between certain dimensions (transverse diameters, original and terminals) of the PV of the male subjects versus the female subjects.

In the classic anatomical descriptions the number of subjects is very limited (1 - 10) and in certain cases the studied number of subjects is not specified [2] [6] where from the difficulties of comparison between our results and those of the anatomical literature.

The length of the PV had been measured by various authors during anatomical dissections (Table 5). We found a single ultrasound study concerning the length of the portal vein.

Our results are little different from those of Delorme and Seymour [6]. The average reported by Rouvière is superior to ours. It could give some explanation by the fact that the conditions of measure are different: measure made by dissection and ultrasound measure.

The diameter of the PV is a more important parameter because it is one of important criteria to make the diagnosis of high pressure in the portal system.

According to certain authors, the normal diameter of the PV measured in hepatic hilum, should not exceed 12 in $15 \mathrm{~mm}$ [7]. The same authors considered that the caliber of the PV is decreasing in the sense of the flow portal [7]. In our sample, we found that the transverse diameters of the PV in its origin and in the ending were respectively $9.05 \pm 2.82 \mathrm{~mm}$ and $9.16 \pm 2.58 \mathrm{~mm}$.

The decreasing caliber of the PV in the sense of the flow portal evoked by Weinreb [7] was not observed in our study.

In the constitution of the PV, intervene two big venous trunks: the spleno mesenteric trunk and the superior mesenteric vein. The place of convergence of 
Table 5. Averages length of the PV according to the authors.

\begin{tabular}{ccc}
\hline Authors & Type of study & Length of the PV \\
\hline Rouvière & Dissection & 10 \\
Delorme & Dissection & 10 \\
Seymour & Dissection & 10 \\
Ongoiba & Echography & 10 \\
Our study & Echography & 1000 \\
\hline
\end{tabular}

these two veins, that is the origin of the portal vein, can be dilated.

In the modal arrangement, the portal vein divides in two branches which penetrate into the liver. In our study this arrangement was observed in $96.7 \%$ of the cases. In $3.3 \%$ of the cases, the portal vein had three branches. We can consider this phenomenon an anatomical variation or a premature division of the portal vein.

\section{Conclusion}

This original study shows the normal dimensions of the portal vein in Malian. These measures can serve in the diagnosis of the portal hypertension.

\section{Authorization of the Ethics Committee}

The Ethics Committee of the Faculty of Medicine and Odontostomatologie gave us its agreement for the realization of this study.

The subjects on which were realized various measures gave their consent for the publication.

\section{Conflicts of Interest}

We, authors of this article declare that there is no conflict of interests.

\section{References}

[1] Chevallier, J.M. and Vitte, E. (2011) The Abdominal Cavity. In: Anatomy of the Trunk, $2^{\text {nd }}$ Edition, Lavoisier, Paris, 276.

[2] Delorme, G. and Gralet, P. (1975) Biliary Pathways. In: Treatise of Radiodiagnosis, Volume 7, Masson et Cie edit, Paris, 25-151.

[3] Delorme, G. and Gralet, P. (1975) The Biliary Ways. In: Treaty of X-Ray Diagnosis, House and Cie edict. Paris, 25-151.

[4] Rouvière, H. (1999) Descriptive and Functional Human Anatomy. $11^{\text {th }}$ édition, Paris, 1978, 696.

[5] Ouologuem, I., Berete, S., Ongoïba, N., Sissoko, F., Traoré, A.K.D., Sidibé, S., et al. (2003) Portal Vein: Ultrasound Anatomy. Morphology, 277, 29-32.

[6] Seymour, I., Schwartz, M.D., Tomshires G., et al. (1999) Principles of Surgery. New York, 2162.

[7] Weinreb, J.C., Kumari, S., Phillips G., et al. (1982) Portal Vein Measurements by Real Time Sonography. American Newspaper of Radiology, 139, 497-499. https://doi.org/10.2214/ajr.139.3.497 